Oswaldo Giannotti, engenheiro agrônomo,

ex-professor visitante da Universidade de

Oswaldo Giannotti

La Plata em curso de pós-graduação sobre defensivos agrícolas. Atualmente é diretor da

Divisão de Defensivos Agrícolas do Instituto

Biológico do Estado de São Paulo.

\title{
Resíduos de defensivos agrícolas nos alimentos
}

\section{Introdução e histórico}

A descoberta e o rápido desenvolvimento do uso dos defensivos organossintéticos nos últimos anos, cuja enorme importância sobre a produtividade agrícola é sobejamente conhecida, ao lado das vantagens que proporcionaram no combate aos insetos nocivos, fungos e outros patógenos e ervas daninhas, reavivaram certos problemas até então nãopesquisados suficientemente e cuja significação à saúde do homem não foi levada na devida consideração. Entre eles, deve-se destacar o que se refere aos possíveis resíduos tóxicos deixados nas plantas e nos animais que se destinam à alimentação do homem. A possibilidade de que a população em geral e os animais domésticos, como decorrência de contaminação do meio ambiente, venham a ingerir pequenas quantidades de inseticidas juntamente com seus alimentos, de forma a causar prejuízos à saúde, tem determinado certa apreensão entre pesquisadores e leigos. É isto perfeitamente justificável, tendo-se em vista pesquisas realizadas nos Estados Unidos da América do Norte, Canadá, América do Sul e na Europa, que demonstraram a existência de significativas quantidades de determinados praguicidas, tais como, DDT, aldrin, dieldrin e $\mathrm{BHC}$, na natureza em geral, como rios, lagos, no solo, nos animais domésticos e silvestres, nos alimentos e finalmente no próprio homem. É preciso ficar bem esclarecido que, de um modo geral, os inseticidas são tóxicos, podendo determinar profundas modificações nas reações básicas e normais do organismo. A biologista norte-americana Rachel Carson em seu famoso livro Silent-spring mostra claramente o que po- de acontecer com o uso inadequado e abusivo dos inseticidas. Desde alterações genéticas até a eliminação da fauna natural e sérios desequilíbrios biológicos, podem ser provocados pelo uso descontrolado de certos defensivos agrícolas. Resta ainda a considerar que, pouco se conhece sobre o seu exato mecanismo de ação tanto para os insetos como para os animais superiores. Embora as pesquisas efetuadas indiquem os fosforados como inibidores de colinesterase, o que aliás é posto em dúvida por certos pesquisadores, pouco se pode dizer sobre os clorados, tanto do grupo do DDT, como dos ciclodienos (aldrin, dieldrin, heptacloro, etc.), e mesmo os mais modernos, como os piretróides, a não ser que se apresentem como estimuladores do sistema nervoso central, através da alteração da permeabilidade da membrana que o envolve ou, provavelmente, pelo bloqueio do potencial de ação, por um mecanismo de inibição da passagem do sódio e potássio através da membrana dos nervos e células nervosas; entretanto, como se origina esse estímulo descontrolado, quais as bases desse mecanismo, nada se conhece.

Diante de fatos como esses, portanto, é indispensável estabelecer-se o limite de periculosidade de tais resíduos, tendo em vista, principalmente, o aspecto crônico ou cumulativo.

O problema é importante, não só no seu aspecto local, isto é, com relação aos possíveis efeitos deletéricos de um inseticida sobre uma determinada comunidade onde aqueles compostos estão sendo usados, como igualmente significante no que respeita ao âmbito internacional, pois a exportação ou im- 
portação de produtos vegetais contendo resíduos poderá criar problemas em outras regiões.

Numerosos exemplos poderiam ser citados para caracterizar a importância do problema.

Assim é que, por volta de 1926, na Inglaterra, maçãs provenientes dos Estados Unidos da América do Norte, provocaram distúrbios patológicos nos consumidores, os quais demonstrou-se terem sidos causados por resíduos de arsênico decorrentes da aplicação de arseniato de chumbo no combate à famosa "broca dos frutos" da macieira. As autoridades inglesas imediatamente suspenderam todas as importações dessa fruta dos Estados Unidos até que os técnicos americanos tomassem medidas sérias a fim de impedir a repetição do fato; a importação somente seria reestabelecida desde o momento em que os resíduos de arsênico estivessem dentro dos limites estabelecidos pelos técnicos britânicos o que obrigou os americanos a uma revisão completa de seus programas de pulverização nos pomares de maçãs, bem como estudar as possibilidades de remoção do excesso de resíduos de arsênico e de chumbo.

Mais recentemente, isto é, em 1929, a população americana viu-se obrigada a não ter em seu menu do dia das graças, os famosos molhos e sucos de cranberry, uma espécie de framboesa silvestre muito apreciada pelos americanos, para serem consumidos com o peru; embora este episódio não tenha ocorrido com inseticidas e sim com um herbicida, o aminotriazol, evidencia muito bem a responsabilidade que cabe aos técnicos que recomendam aplicações dessas drogas, sejam elas inseticidas, fungicidas, herbicidas, etc.

Foi suficiente que técnicos determinassem traços de resíduos dessa substância, conhecida como cancerígena, em algumas partidas de cranberry postas no comércio, para que as autoridades dessem um alarma geral ao povo, solicitando que as apreciadas frutinhas não fossem consumidas. Especialistas consultados afirmaram que não havia perigo, pois para que se desenvolvessem o efeito patológico, de acordo com os dados conhecidos e tendo em vista a pequena quantidade de resíduos encontrada, isto é, apenas traços, cada americano deveria consumir cerca de 5.000 quilos de frutas contaminadas. Apesar disso, todas as medidas foram tomadas a fim de que a população não estivesse exposta ao menor risco e, nessas condições, as autoridades do governo continuaram a merecer a devida confiança da população em geral.

Em nosso continente, outros exemplos podem ser citados.

Pesquisas realizadas na Escola Superior de
Agricultura Luiz de Queiroz - ESALQ, em 1945, no sentido de demonstrar a toxicidade do arsênico para plantas de algodão, como resultado de sua provável acumulação em solos cultivados com essa planta e decorrente da aplicação de arseniato de chumbo para controle de pragas que atacam essa malvácea; aplicação de compostos orgânicos de mercúrio destinados à desinfecção de sementes sob a forma inadequada de pulverização em hortaliças e legumes, determinando a presença de resíduos altamente prejudiciais de mercúrio nos mesmos; contaminação da soja cultivada no Rio Grande do Sul por endrin; contaminação dos produtos hortifrutigranjeiros e certas frutas no Estado de São Paulo pelos clorados aldrin, dieldrin, DDT e endrin que, embora dentro dos limites dos resíduos nãointencionais, cuja signjficação será discutida mais adiante, constitui um alerta para a tomada de medidas legislativas que restrinjam o uso desses defensivos entre nós; presença de resíduos de ciclodienos (aldrin e dieldrin) em alpiste importado de outros países da América do Sul, ocasionando entre os criadores do Estado de São Paulo a morte de inúmeros pássaros; presença de resíduos de pequenas quantidades de defensivos clorados (aldrin, dieldrin, endrin e DDT) em solos agriculturáveis do Estado de São Paulo, que poderão se transformar em significativas fontes de contaminação de diversas culturas.

Outros exemplos poderiam ser citados, entretanto, esses casos parecem suficientes para mostrar a importância do problema. Não temos conhecimento de que os inseticidas modernos tenham sido responsáveis por intoxicações coletivas, decorrentes do consumo de alimentos contaminados em conseqüência de tratamentos químicos de lavouras. Entretanto, tendo em vista suas características físico-químicas, tais como, a absorção nos diferentes meios existentes na natureza, estabilidade química e metabolização para compostos mais tóxicos, podemos admitir que isso poderá ocorrer, desde que não se tomem medidas adequadas de precaução.

\section{Definições e conceitos}

\section{O que é resíduo}

Para se ter uma exata compreensão do problema, será necessário, antes de mais nada, saber-se o que é resíduo, como se processa a sua formação e quais os fatores que contribuem para agravar a sua presença.

À primeira vista, o resíduo poderia ser interpretado como simples camada de inseticida que recobre as folhas, frutos ou raízes das plantas, depois da aplicação dos mesmos; tal camada, entretanto, deve ser considerada apenas como um depósito de material. Desde que essa camada venha a sofrer a 
ação dos fatores do clima, como chuva, vento, etc., o que fica absorvido em maior ou menor quantidade nas plantas é que deve ser verdadeiramente considerado como resíduo. Essa absorção se processa com maior ou menor intensidade, pelo fato dos inseticidas orgânicos modernos, em sua maioria, serem lipossolúveis, isto é, dissolverem-se nos óleos e nas camadas cerosas que recobrem as plantas e, ali permanecerem por tempo variável, dependendo, essencialmente, de sua solubilidade nessas camadas e de sua estabilidade química. Quanto aos inseticidas sistêmicos, pelas suas próprias características bioquímicas, incorporam-se à seiva dos vegetais, circulando na planta e aí permanecendo, inalterado ou transformado em metabólicos tóxicos por tempo variável, de acordo com suas propriedades químicas. O que caracteriza, então, o resíduo de um certo inseticida para um determinado tipo de vegetal, é o que os técnicos denominaram "vida média do resíduo", isto é, o tempo necessário para que o resíduo inicial, que é determinado logo após a sua aplicação, se reduza à metade.

A tabela 1 mostra um exemplo extraído dos trabalhos de pesquisadores brasileiros sobre a longevidade do mevinphos em couve-flor, dados em ppm (partes por milhão). couve-flor

TABELA 1 - Resíduos de mevinphos em Dias depois do tratamento Resíduos do inseticida(ppm)

\begin{tabular}{l|r}
\hline 1 & 2,5 \\
2 & 1,8 \\
3 & 0,7 \\
4 & 0,4 \\
5 & 0,05 \\
6 & 0,01 \\
\hline
\end{tabular}

Verifica-se que a vida média do resíduo desse inseticida está ao redor de três dias.

Essa característica, entretanto, varia de acordo com o tipo de concentração do inseticida, com o local e com a espécie de planta, o que, evidentemente, vem complicar o problema, uma vez que há a necessidade de se investigar cada caso individualmente, e dentro de determinadas condições climáticas.

De um modo geral, entretanto, podemos dividir os inseticidas em um grupo altamente residual e outro que é constituído de inseticidas que se decompõe mais ou menos rapidamente, considerando, é óbvio, que as aplicações iniciais sejam feitas nas concentrações normais, isto é, que sejam aquelas recomendadas para o controle das pragas, doenças e ervas daninhas.

A tabela 2 nos dá uma idéia dessa caracterís- tica tendo em conta alguns dos inseticidas mais usados e diversas espécies de plantas.

\begin{tabular}{|c|c|c|c|c|}
\hline Inseticidas & Plantas & $\begin{array}{l}\text { Residuo } \\
\text { Inicial }\end{array}$ & $\begin{array}{l}\text { ppm. } \\
\text { após } \\
24 \text { hs. }\end{array}$ & $\begin{array}{c}\text { Vida média em } \\
\text { dias }\end{array}$ \\
\hline $\begin{array}{l}\text { BHC } \\
\text { Toxafeno } \\
\text { DDT } \\
\text { DDT } \\
\text { DDT }\end{array}$ & $\begin{array}{l}\text { Alfafa } \\
\text { Alfafa } \\
\text { Alfafa } \\
\text { Citros (folhas) } \\
\text { Citros } \\
\text { (casca de fruto) }\end{array}$ & $\begin{array}{l}17 \\
30 \\
13 \\
35 \\
40\end{array}$ & $\begin{array}{r}4,6 \\
16 \\
5,0 \\
27,0 \\
25,0\end{array}$ & $\begin{array}{r}7 \\
16 \\
6 \\
39 \\
26\end{array}$ \\
\hline $\begin{array}{l}\text { DDT } \\
\text { DDT }\end{array}$ & $\begin{array}{l}\text { Alface } \\
\text { Pessegueiro } \\
\text { (frutos) }\end{array}$ & $\begin{array}{r}30 \\
8,6\end{array}$ & $\begin{array}{l}1,3 \\
60\end{array}$ & 28 \\
\hline DDT & $\begin{array}{l}\text { Pessegueiro } \\
\text { (folhas) }\end{array}$ & 290 & 125 & 12 \\
\hline Dieldrin & $\begin{array}{l}\text { Macieira } \\
\text { (folhas) }\end{array}$ & 110 & 41 & 10 \\
\hline Dieldrin & $\begin{array}{l}\text { Pessegueiro } \\
\text { (frutos) }\end{array}$ & 65 & 1,9 & 8 \\
\hline Dieldrin & $\begin{array}{l}\text { Pessegueiro } \\
\text { (folhas) }\end{array}$ & 25 & 6,5 & 7 \\
\hline $\begin{array}{l}\text { Malathion } \\
\text { Malathion } \\
\text { Malathion }\end{array}$ & $\begin{array}{l}\text { Macieira (frutos) } \\
\text { Alface } \\
\text { Pessegueiro }\end{array}$ & $\begin{array}{r}2,8 \\
40,0 \\
9\end{array}$ & $\begin{array}{r}\text { traços } \\
\text { traços } \\
1,2\end{array}$ & $\begin{array}{l}3 \\
2 \\
5\end{array}$ \\
\hline $\begin{array}{l}\text { Malathion } \\
\text { Parathion } \\
\text { Parathion }\end{array}$ & $\begin{array}{l}\text { (frutos) } \\
\text { Tomate } \\
\text { Alface } \\
\text { Macieira } \\
\text { (frutos) }\end{array}$ & $\begin{array}{r}10 \\
1,5 \\
4\end{array}$ & $\begin{array}{r}\text { traços } \\
0,2 \\
0,8\end{array}$ & $\begin{array}{l}2 \\
6 \\
6\end{array}$ \\
\hline Parathion & $\begin{array}{l}\text { Macieira } \\
\text { (folhas) }\end{array}$ & 60 & 2 & 2 \\
\hline $\begin{array}{l}\text { Parathion } \\
\text { Parathion }\end{array}$ & $\begin{array}{l}\text { Alface } \\
\text { Pessegueiro }\end{array}$ & $\begin{array}{l}2,2 \\
3,5\end{array}$ & $\begin{array}{r}\text { traços } \\
0,9\end{array}$ & $\begin{array}{l}2 \\
7\end{array}$ \\
\hline Parathion & $\begin{array}{l}\text { (rutos) } \\
\text { Pessegueiro } \\
\text { (folhas) }\end{array}$ & 0,6 & 0,2 & 2 \\
\hline Parathion & $\begin{array}{l}\text { Tomateiro } \\
\text { (frutos) }\end{array}$ & 0,95 & 0,15 & 7 \\
\hline Metil-parathion & $\begin{array}{l}\text { Macieira } \\
\text { (folhas) }\end{array}$ & 40 & 2 & 3 \\
\hline Dimeton-metil & $\begin{array}{l}\text { Tomateiro } \\
\text { (folhas) }\end{array}$ & 6 & 1 & 7 \\
\hline Denetib netuk & $\begin{array}{l}\text { Tomateiro } \\
\text { (frutos) }^{1}\end{array}$ & $\begin{array}{l}\text { não-de } \\
\text { apco } \\
\text { do }\end{array}$ & $\begin{array}{l}\text { minável } \\
4 \text { horas } \\
\text { amento }\end{array}$ & \\
\hline Carbaryl & $\begin{array}{l}\text { Tomateiro } \\
\text { (frutos) }\end{array}$ & & 0,28 & 4 \\
\hline
\end{tabular}

I. Determinação como "sulfona" do Dimeton-metil.

Verifica-se por esta tabela, que os inseticidas clorados têm uma tendência em formar resíduos mais persistentes, ocorrendo o contrário com os fosforados e os carbamatos. Essas observações devem-se principalmente à maior estabilidade química dos clorados. Além disso, a natureza da superfície em que é depositado o inseticida, bem como o tipo de formulação, tem certa influência na permanência do resíduo. De um modo geral, as emulsões dão ao inseticida um maior poder de penetração, contribuindo, assim, para a formação de resíduos mais estáveis do que no caso dos polvilhamentos ou pós molháveis. Finalmente, os inseticidas sistêmicos, sendo absorvidos pelas plantas e, portanto, tornando-se protegidos das ações dos fatores do clima, determinam o aparecimento de 
resíduos bastante estáveis e perigosos para a saúde humana. É necessário, portanto, conhecer-se exatamente o comportamento bioquímico dessas substâncias nas plantas, a fim de que possam ser aplicadas com segurança.

\section{Inseticidas que se modificam durante a formação dos resíduos tóxicos}

É um aspecto extremamente importante na formação de resíduos tóxicos, uma vez que, certos inseticidas se modificam durante o processo de degradação que sofrem, transformando-se em substâncias tão ou mais tóxicas do que o inseticida original. Assim é que o aldrin transforma-se na sua forma correspondente epoxi, e que nada mais é do que o dieldrin. Transformação idêntica sofre o heptacloro. Entre os fosforados, essas reações são mais comuns, sendo que os tiofosfatos são metabolizados para fosfatos, geralmente de atividades mais tóxicas, e, finalmente, para fosfatos orgânicos simplesmente não-tóxicos, e até certo ponto utilizáveis pelas plantas. Essas modificações são ainda mais pronunciadas nos sistêmicos e em certos inseticidas com ação de profundidade, parecendo, entretanto, que em todos os casos o objetivo final é a degradação total do composto para substâncias não-tóxicas do que as substâncias originais.

\section{Resíduos provenientes de aplicações de inseticidas no solo}

É evidente que não só as aplicações de inseticidas na parte aérea das plantas determinam a formação de resíduos. Em grande número de casos os entomólogos vêem-se obrigados a recomendar o uso dessas substâncias, para o controle de pragas que vivem no solo, que ali alimentando-se prejudicam a produção de certos tipos de raízes e tubérculos utilizados na alimentação dos homens e dos animais. Há evidências de que essas partes hipógeas das plantas absorvem, embora em pequena quantidade, certas espécies de inseticidas. Esse fato pode ser verificado na tabela 3.

Nota-se que, nas concentrações usualmente recomendadas a que se referem os dados dessa tabela, o resíduo é insignificante, e está perfeitamente dentro dos limites de segurança estabelecidos pelos especialistas; entretanto, esses dados indicam que não devem ser usadas concentrações superiores às recomendadas sem correr o risco do aparecimento de resíduos perigosos. Os próprios inseticidas sistêmicos de longa ação residual, como o phorate, disulfoton, aldicarb e outros podem ser usados nesses casos, desde que se conheça exatamente o
TABELA 3 - Absorção de diferentes tipos de inseticidas por diversas culturas de raízes e tubérculos

\begin{tabular}{l|l|r}
\hline Inseticidas & Planta & Resíduos em ppm. \\
\hline Aldrin & Cenoura & 0,4 \\
Aldrin & Batatinha & 0,05 \\
BHC & Batatinha & 0,15 \\
Clordane & Cenoura & 1,4 \\
Clordane & Batatinha & 0,08 \\
DDT & Cenoura & 0,5 \\
DDT & Batatinha & 0,02 \\
Dieldrin & Cenoura & 0,7 \\
Dieldrin & Batatinha & 0,03 \\
Endrin & Cenoura & 0,7 \\
Heptaclor & Cenoura & 0,9 \\
Heptaclor & Batatinha & 0,18 \\
Lindane & Cenoura & 1,0 \\
Lindane & Amendoim & 0,1 \\
Parathion & Batatinha & 0,01 \\
Camphechlor & Cenoura & 1,0 \\
Camphechlor & Batatinha & 0,04 \\
\hline
\end{tabular}

tempo de seu metabolismo dentro da planta, podendo-se então recomendá-los com segurança.

\section{Tipos de resíduos}

Falamos, até o momento, da inter-relação direta entre a formação de resíduos e a aplicação de defensivos agrícolas, considerando-se o uso da "boa prática agrícola", isto é, o emprego dos defensivos na concentração certa, época mais adequada e formulação mais conveniente. Evidentemente esses fatores são variáveis de país para país e de região para região, entretanto são eles que contribuem para a formação dos "resíduos tolerância", na sua máxima concentração e expressos em ppm., permitindo, ao mesmo tempo, um satisfatório controle das pragas, das doenças e ervas daninhas que se deseja combater.

Além desse tipo de resíduo, entretanto, pode ocorrer o que se conhece como "resíduo não-intencional", cujo aparecimento decorre da contaminação ambiental, causada pela aplicação dos defensivos capazes de poluir o ambiente. Este tipo de resíduo ocorre, normalmente, como resultado do fenômeno de bioconcentração dessas substâncias, através da cadeia alimentar dos organismos. Assim é que poderemos ter resíduos em culturas efetuadas em solos já contaminados anteriormente pelo uso de defensivos estáveis, o que irá determinar a contaminação da carne, leite, ovos, etc., provenientes da alimentação dos animais, com rações preparadas a partir da colheita dessas culturas. No caso de peixes, e outros animais aquáticos, a contaminação mais provável se dá através do contato permanente desses animais com a água. A única forma de controlar esse tipo de resíduo é eliminar as fontes de contamina- 
ção, através do uso de compostos químicos igualmente eficiente, porém de baixo efeito residual. A legislação brasileira, através do Ministério da Agricultura, proíbe o uso de alguns desses inseticidas em determinadas lavouras, como fumo, hortaliças, pastagens e fruticultura; entretanto, permite o uso extensivo em grandes culturas, como algodão, soja e amendoin, principalmente; o que não elimina as possibilidades de contaminação de nossos solos. Por outro lado, o Ministério de Saúde tem regulamentado, através do cadastramento dos defensivos agrícolas registrados no Ministério da Agricultura, as principais características e uso dos mesmos, os níveis de tolerância de resíduos permitidos, incluindo os "não-intencionais", isto é, como já foi dito, decorrentes da contaminação ambiental. A única medida no sentido de impedir que estes tipos de resíduos se tornem perigosos, atingindo limites além daqueles permitidos pelas pesquisas toxicológicas, é proibir o uso generalizado dessas substâncias poluentes, o que aliás foi determinado na maioria dos países da Europa, Canadá, Japão e outros.

Pesquisas recentes no Instituto Biológico do Estado de São Paulo, têm demonstrado que alguns solos agriculturáveis no Estado de São Paulo, se apresentam contaminados, embora com quantidades pequenas, por defensivos agrícolas clorados, de longa estabilidade, como o aldrin, dieldrin, endrin, DDT e BHC, o que ocorre com muito maior intensidade em outros países, principalmente os mais desenvolvidos, onde o uso dessas substâncias foi bastante generalizado. As tabelas 4, 5 e 6 nos dão uma idéia dessa contaminação, que é, como já foi dito, a causadora da formação dos "resíduos não-intencionais".

\section{Estabelecimento dos níveis de tolerância dos diversos inseticidas para diferentes espécies vegetais}

Uma vez conhecido o mecanismo essencial da formação dos resíduos tóxicos e suas características específicas para cada tipo de planta e de inseticida, é imprescindível o conhecimento da provável toxicidade dos inseticidas tanto do ponto de vista agudo como crônico para os homens e animais domésticos, a fim de se estabelecer os níveis de tolerância com ponderável margem de segurança. É indispensável, portanto, que se conheça muito bem não só a toxicidade aguda de cada composto, bem como, e principalmente, seu efeito crônico sobre os organismos animais. Esses trabalhos têm sido desenvolvidos com bastante intensidade em diversos países, como nos Estados Unidos da América do Norte, no Canadá, na Inglaterra, na França e outros.

As tabelas 7 e 8 contêm resumidamente esses dados, sendo que na última coluna são apresentados os limites de tolerância geralmente aceitos pelos especialistas.

O critério para o estabelecimento dos níveis de tolerância é empírico, tornando-se necessário algu-

TABELA 4 - Resíduos médios ( $\mathrm{mg} / \mathrm{kg}$ ), em valores máximos e mínimos, de defensivos agrícolas clorados encontrados em solos de fruticultura, em diferentes regiões.

\begin{tabular}{l|r|c|c|c|c|c}
\hline País & DDT $^{1}$ & BHC $^{2}$ & Aldrin & Dieldrin & Endrin & Toxafeno \\
\hline EUA & $\begin{array}{r}122,60 \\
8,29\end{array}$ & $\begin{array}{c}0,05 \\
-\end{array}$ & $\begin{array}{c}0,02 \\
-\end{array}$ & $\begin{array}{c}1,41 \\
0,19\end{array}$ & $\begin{array}{c}6,30 \\
-\end{array}$ & $\begin{array}{c}7,72 \\
-\end{array}$ \\
\hline Inglaterra & 6,03 & - & - & - & - & - \\
\hline Canadá & 109,85 & - & 0,03 & - & - & - \\
\hline $\begin{array}{l}\text { Brasil (Estado de } \\
\text { São Paulo) }\end{array}$ & $\begin{array}{r}0,03 \\
\text { traços }\end{array}$ & $\begin{array}{c}0,012 \\
\text { traços }\end{array}$ & $\begin{array}{c}0,03 \\
\text { traços }\end{array}$ & $\begin{array}{c}0,12 \\
\text { traços }\end{array}$ & $\begin{array}{c}0,09 \\
\text { traços }\end{array}$ & - \\
\hline
\end{tabular}

1. DDT e compostos correlatos.

2. Soma dos isômeros.

TABELA 5 - Resíduos médios (mg/ $\mathrm{kg}$ ), em valores máximos e mínimos, de defensivos agrícolas clorados, encontrados em solos de horticultura, em diferentes regiões.

\begin{tabular}{l|c|c|c|c|c|c}
\hline País & DDT & BHC & Aldrin & Dieldrin & Endrin & Toxafeno \\
\hline EUA & 3,70 & 0,12 & 0,06 & 2,08 & 0,01 & 1,0 \\
Canadá & 0,19 & 0,001 & 0,02 & 0,04 & traços & - \\
& 24,26 & - & 0,71 & 1,55 & 1,70 & - \\
\hline Inglaterra & 0,77 & - & 0,01 & 0,01 & - & - \\
\hline Brasil & - & - & - & 0,67 & - & - \\
\hline
\end{tabular}

TABELA 6 - Resíduos médios $(\mathrm{mg} / \mathrm{kg}$ ) em valores máximos e minimos, de defensivos agrícolas clorados encontrados em solos de grándes lavouras', em diferentes regiões.

\begin{tabular}{l|c|c|c|c|c|c}
\hline País & DDT & BHC & Aldrin & Dieldrii & Endrin & Toxafeno \\
\hline EUA & 15,10 & 0,26 & 0,23 & 0,79 & 0,06 & 0,13 \\
& 0,02 & 0,01 & traços & 0,02 & 0,01 & 0,07 \\
\hline Canadá & 4,61 & - & 0,48 & 1,08 & 1,48 & - \\
& 0,40 & - & 0,01 & 0,05 & 0,09 & - \\
\hline Inglaterra & 0,30 & - & 0,15 & 0,15 & - & - \\
\hline Brasil & 0,20 & 0,01 & 0,02 & 0,02 & - & - \\
\hline
\end{tabular}

1. Algodão, café, milho, arroz, amendoim e outros. 
mas consideraç̃es para ajudar a interpretar os dados das tabelas 7 e 8. Eles se referem a animais comumente empregados em laboratório para esse tipo de trabalho, ou sejam, ratos e camundongos. Tanto para a intoxicação aguda como crônica, os inseticidas são dados oralmente, apenas que, no primeiro caso, as mortalidades são observadas por um período de 24-48 horas e no segundo são feitas observações por tempo superior a seis ou doze meses sobre a influência dessa substância no crescimento, na reprodução e nas alterações patológicas que possa sobreviver nos diversos órgãos (carcinogênese); além disso, os mecanismos de degradação metabólica, formação de metabolitos tóxicos e vias de eliminação desses defensivos são exaustivamente investigados.

Note-se que na terceira coluna, onde são dadas as quantidades de inseticidas colocadas na ração a ser fornecida para animais, no caso dos clorados, elas são as quantidades mínimas que ocasionam alterações no organismo, e para os fosforados são as que não ocasionam alteração alguma visível. Do ponto de vista da intoxicação crônica, deve-se fazer uma distinção de ordem geral entre os clorados e os fosforados e carbamatos, extremamente importantes na apreciação desses problemas; os clorados, via de regra, são dotados de grande estabilidade e, mesmo no organismo, são difíceis ou lentamente metabolizados mesmo quando dados em quantidades pequenas; enquanto isso, os fosforados são metabolizados com relativa rapidez, tanto nas plantas como nos animais. Temos, pois, situações bem diferentes, pois enquanto os derivados clorados, deixam de um modo geral, resíduos mais pronunciados, de outro lado, os fosforados são dotados, geralmente, de baixo poder residual, não se acumulando nos organismos superiores.

É por esse motivo, provavelmente, que apesar do aldrin ser menos tóxico do que o parathion, do ponto de vista da intoxicação aguda, o nível de tolerância permitido para esse último é dez vezes superior (1,0 parathion e 0,1 aldrin).

A mesma comparação poderia ser feita entre o endrin e o azinphos metil. Podem-se notar, entretanto, algumas exceções não muito fáceis de serem compreendidas. Assim é que para o diazinon, cuja toxicidade aguda é do mesmo nível que o DDT, embora sem efeito cumulativo mesmo em doses elevadas, o resíduo tolerável é dez vezes menor do que o DDT. Entretanto, mesmo entre os clorados poderemos notar que para alguns deles os níveis de tolerância são bem elevados; estão nesse caso o toxafeno, o lindane e o metoxicloro, indicando que esses três compostos são metabolizados com relativa facilidade pelos organismos animais.

Conhecendo-se esses níveis sem efeito toxi- cológico, pode-se calcular a injestão diária aceitável (IDA) que os animais podem suportar sem risco, considerando-se os resíduos deixados nas diferentes espécies vegetais ou animais que são usados na alimentação do homem, tendo em vista a boa prática agrícola, isto é, emprego de concentrações recomendadas na época adequada, no sentido de se ob-

TABELA 7 - Características toxicológicas de alguns inseticidas clorados, carbamatos e outros.

\begin{tabular}{|c|c|c|c|c|}
\hline Inseticida & $\begin{array}{r}\text { Toxicidade } \\
\text { Aguda }^{1}\end{array}$ & $\begin{array}{r}\text { Toxicidade } \\
\text { Crônica }\end{array}$ & $\mathrm{IDA}^{3}$ & $\begin{array}{r}\text { Resíduos } \\
\text { Permitidos } \\
\text { (ppm) }\end{array}$ \\
\hline $\begin{array}{l}\text { Aldrin } 5 \\
\text { Toxafeno }^{5} \\
\text { DDT }^{5} \\
\text { Endrin } \\
\text { Heptacloro } \\
\text { Lindane } \\
\text { Cloro } \\
\text { Benzilato } \\
\text { Metoxicloro } \\
\text { Endosulfan } \\
\text { Carbaryl } \\
\text { Aldicarb } \\
\text { Methomyl } \\
\text { Carbofuran } \\
\text { Deltametrina } \\
\text { Fenvalerato } \\
\text { Permetrina } \\
\text { Cypernetrina } \\
\text { Flucythrimato } \\
\text { (Pay-off) }\end{array}$ & $\begin{array}{r}25-67 \\
25 \\
250 \\
10-12 \\
90 \\
125 \\
700-800 \\
6.000 \\
110 \\
540 \\
10 \\
1724 \\
130-4000 \\
450 \\
200-800 \\
67-81\end{array}$ & $\begin{array}{r}5 \\
100 \\
5 \\
30 \\
400 \\
500 \\
200 \\
\\
2,5 \\
20 \\
50-100 \\
30-250 \\
100 \\
100-300 \\
120-300\end{array}$ & $\begin{array}{r}0,0075 \\
0,01 \\
0,001 \\
0,0005 \\
0,0075 \\
0,007 \\
0,03 \\
0,05\end{array}$ & $\begin{array}{r}0,1 \\
7,0 \\
0,02-0,1 \\
0-0,02 \\
10,0 \\
0,5-2,0 \\
14 \\
0,10-2,0 \\
0,2-10 \\
0,01-0,5 \\
0,05-2,0\end{array}$ \\
\hline
\end{tabular}

1. DL. $50 \mathrm{mg} / \mathrm{kg}$

2. ppm. na ração que começam causar alterações no organismo

3. Ingestão diária aceitável

4. Embora contenham cloro na molécula, não se acumulam no organismo animal

5. Cancerígenos para animais de laboratório.

TABELA 8 - Características toxicológicas de alguns inseticidas fosforados.

\begin{tabular}{|c|c|c|c|c|}
\hline Inseticida & $\begin{array}{r}\text { Toxicidade } \\
\text { Aguda }^{1}\end{array}$ & $\begin{array}{r}\text { Toxicidade } \\
\text { Crônica }^{2}\end{array}$ & $\mathrm{IDA}^{3}$ & $\begin{array}{r}\text { Resíduos } \\
\text { Permitidos } \\
\text { (ppm) }\end{array}$ \\
\hline $\begin{array}{l}\text { Azinfos-etil } \\
\text { Diazinon } \\
\text { Fenthion } \\
\text { Malathion } \\
\text { Metil-parathion } \\
\text { Carbophenothion } \\
\text { Triclorfon } \\
\text { Disulfoton } \\
\text { Thiometon } \\
\text { Dimeton-metil } \\
\text { Mevinphos } \\
\text { Phorate } \\
\text { Fenitrothion } \\
\text { Dimetoato } \\
\text { Clorfenvinfos } \\
\text { Monocrotofos }\end{array}$ & $\begin{array}{r}15-25 \\
220-270 \\
200-220 \\
1.200-1.500 \\
14-42 \\
200 \\
450-550 \\
8-10 \\
190 \\
120 \\
5 \\
1.7 \\
250-1.250 \\
215 \\
30-120 \\
21\end{array}$ & $\begin{array}{r}30 \\
1.000 \\
1.000 \\
20 \\
3 \\
2 \\
25-50 \\
2,5 \\
200 \\
300\end{array}$ & $\begin{array}{r}0,001 \\
0,002 \\
0,0005 \\
0,02 \\
0,001 \\
0,0005 \\
0,005 \\
0,002 \\
\\
0,0015 \\
0,001 \\
0,005\end{array}$ & $\begin{array}{r}0,2-2,0 \\
0,1-0,75 \\
0,1-0,0 \\
0,5-0,8 \\
0,05-1,0 \\
0,02-0,8 \\
0,05-0,2 \\
0,1-0,5 \\
0,05-0,4 \\
0,05-0,4 \\
0,1-1,0 \\
0,1-0,5 \\
0,05-0,5 \\
0,0-2,0 \\
0,05-0,2 \\
0,05-0,1\end{array}$ \\
\hline
\end{tabular}

1. DL. $50 \mathrm{mg} / \mathrm{kg}$

2. ppm. na ração que não causam alterações no organismo

3. Ingestão diária aceitável. 
ter um controle satistatório da praga, doença ou erva daninha, pode-se estimar a quantidade de defensivos agrícolas que será ingerido pelo homem diariamente, levando-se em consideração os componentes básicos de suas refeições. Esta quantidade, evidentemente, deverá ser menor do que a IDA, e é tomada por base para cálculo dos níveis residuais de tolerância.

Em suma, verifica-se que, no estabelecimento dos níveis de tolerância dos diversos tóxicos, são levados em consideração não só a toxicidade aguda, mas, principalmente, a toxicidade crônica.

Apesar de todo esse trabalho cauteloso, poderiam surgir dúvidas e divergências; assim, tendo em vista que em sua maioria essas substâncias, e principalmente os clorados, agem sobre o sistema nervoso de uma forma ainda completamente desconhecida, poder-se-ia argumentar se não haveria um prejudicial efeito dos mesmos nos comportamento neurofisiológico desses animais ainda que administrados em doses toleráveis. Embora aceitável, esse argumento precisa ser comprovado.

O que os trabalhos experimentais têm demonstrado e os dados até agora expostos, como sendo um resumo dos mesmos, é que o uso dos inseticidas deve ser feito com extremo cuidado.

Ainda no que se refere ao estabelecimento dos níveis de tolerância dos resíduos, é necessário esclarecer que os números dados nas tabelas são de ordem geral; dependendo do tipo de alimento, essas tolerâncias são mais rigorosas, chegando mesmo a não existir. Neste caso são incluídos os vegetais ou derivados animais que entram quase que diariamente na dieta do homem ou dos animais domésticos. Assim, nos Estados Unidos da América do Norte, na Europa e no Japão, não é permitido o uso de inseticidas estáveis e dificilmente metabolizados pelo organismo, em mistura com os grãos e cereais armazenados; por outro lado, em outras condições, as partes comestíveis dos vegetais acham-se tão bem protegidas que dificilmente as substâncias aplicadas podem atingi-las, permitindo, então, maior segurança no uso das mesmas.

Mais recentemente, foi proibido, pura e simplesmente, o uso do DDT e outros clorados nesses países, pela propensa contaminação do meio ambiente por meio dele; é necessário realçar, entretanto, que recrudesceram alguns problemas entomológicos em que esse inseticida era a base para o controle químico das pragas.

\section{Como evitar a formação de resíduos perigosos}

Pesquisas relativas aos aspectos químicos e bioquímicos dos inseticidas, bem como cuidadosas investigações entomológicas sobre quais as épocas mais propícias para a aplicação dos mesmos sem perigo de contaminar os alimentos, nos fornecem os meios para o seu uso racional.

Os numerosos produtos desenvolvidos comercialmente entre nós, permitem escolher os mais apropriados para cada caso. Assimé que, não devem ser recomendados os produtos de longo efeito residual para tratamento de plantas que são diretamente consumidas pelo homem ou animais domésticos. No caso de ser necessária tal recomendação, é indispensável esperar um período de tempo necessário para que o resíduo desapareça ou persista em quantidade não-perigosa. Existem produtos que, sistêmicos ou não, são rapidamente degradados para compostos não-tóxicos, o que possibilita o uso dos mesmos em períodos próximos à colheita.

De um modo geral, o período de tempo, em dias, que deve ser respeitado, para os diferentes inseticidas, entre a aplicação e a colheita é o seguinte: etil-parathion 7 a 21; metil-parathion 7 a 21; malathion 1 a 14; dimeton metil e outros sistêmicos em pulverização 21; mevinphos 1 a 3 e excepcionalmente 14 ; diazinon 7 a 14 ; carbofenothion 7 a 30 ; azinfosetil 7 a 30; metoxicloro 3 a 14; dicofol 7 a 30; carbaryl 1 a 5 ; endosulfan 7 a 14 ; lindane 7 a 20 ; endrin 35 a 60; TDE 7 a 30; DDT 7 a 30; camphechlor 7 a 14 ; fenthion 14 ; trichlorfon 14 a 28.

A variação observada deve-se principalmente à espécie de vegetal considerado e às propriedades tóxicas do composto. De um modo geral, entretanto, os limites maiores se referem a hortaliças, frutas, forrageiras, cereais e outros produtos agrícolas que são diretamente consumidos pelo homem ou animais domésticos. Os limites inferiores, devem ser considerados. para os produtos agricolas que são manipulados, antes que venham a ser empregados na alimentação. Além do tipo de defensivos a ser usado, a época adequada de aplicação é fator decisivo na obtenção de resultados positivos. Os inseticidas devem ser aplicados unicamente quando se verifica a presença da praga, o que pode ser feito por inspeção visual e através de armadilhas que atraem as pragas, como o uso de feromônios, e armadilhas luminosas; fungicidas têm sua aplicação preferencial na época do início de esporulação dos fungos e outros patógenös, que pode ser determinada através de minuciosas pesquisas de epidemiologia dos mesmos ou por dispositivos coletores de esporos; e finalmente os herbicidas deverão ser aplicados nos períodos de maior competição entre as ervas daninhas e os cultivares.

O controle químico das pragas, doenças e ervas daninhas deve ser considerado apenas uma me- 
dida, dentre as que devem ser basicamente aplicadas, e que constituem o que modernamente se denomina "controle integrado". Assim é que o controle biológico, emprego de variedades de cultivares resistentes ou de ciclo mais adequado, época de plantio apropriado, rotação de cultura, e outras, são de grande valor no controle das pragas e doenças.

\section{Atuação das instituições governamentais e privadas e recomendação de ordem geral.}

As responsabilidades governamentais relativas à pesquisa e administração dos problemas inerentes aos resíduos de defensivos agrícolas nos alimentos consumidos pela população e os animais domésticos, estão afetos, basicamente, a três áreas de atividades, de cuja ação conjunta e harmoniosa deverão ser encontradas as soluções a tão importantes questões. Os aspectos toxicológicos, deverão ser investigados pelos departamentos da área de saúde, cujos objetivos têm por finalidade verificar a toxicidade aguda e crônica, bem como, o comportamento bioquímico dessas substâncias nos vertebrados, observando-se o processo de degradação ou ativação das mesmas, uma vez introduzidas no organismo, quais as reações vitais afetadas e, principalmente, determinar quais as quantidades mínimas que podem ser ingeridas pelos animais juntamente com suas rações, sem que o seu organismo seja prejudicado, principalmente no que respeita à longevidade e alterações nos principais órgãos de sua constituição, o que é básico na determinação da ingestão diária aceitável (IDA); também deverão ser intensamente estudados os possíveis efeitos sobre as enzimas e a reprodução (teratogênese) e suas características cancerígenas, mutagênicas e outros parâmetros biológicos.

No que respeita a área agronômica, deverão ser feitas determinações quantitativas sobre a utilização dos defensivos agrícolas na agricultura para os diferentes tipos de lavouras, bem como observações sobre as interferências na eliminação de inimigos naturais (controle biológico), no comportamento bioquímico sobre as plantas e animais domésticos (formação dos diferentes tipos de resíduos), no acúmulo nos diferentes tipos de solo e na água (rios, lagos e mananciais), quais as épocas mais apropriadas de sua aplicação, quais os períodos. Deve-se procurar, de forma sintética e de acordo com o que define o Codex alimentarius, estabelecer a "boa prática agrícola" onde, tendo os parâmetros anteriormente citados bem-determinados, torna-se possivel organizar um programa fitossanitário para o controle das pragas, doenças e ervas daninhas que prejudicam nossa agricultura; obedecidos esses parâme- tros, espera-se obter um controle eficiente, sem aparecimento de problemas colaterais prejudiciais.

Finalmente, aos órgãos responsáveis pela proteção do meio ambiente caberá a complementação de toda essa atividade, objetivando impedir a utilização de tecnologia que possa vir comprometer a vida dos organismos de nossa fauna terrestre e aquática, monitorando, por meio de laboratórios especializados e distribuídos por todo o país, a presença de substâncias químicas com características poluentes do meio ambiente. Sem uma estrutura técnicocientífica atuante, torna-se difícil ou impossivel estabelecer e fazer cumprir legislação sobre o problema.

É fundamental que todos os que têm certa responsabilidade no problema, sejam eles técnicos do governo, encarregados de elaborar ou divulgar instruções técnicas de firmas particulares, vendedores, comerciantes, industriais e os próprios lavradores, colaborem sensatamente na solução do mesmo. Assim como um vendedor, um técnico, um industrial ou comerciante, não deve recomendar para o controle de determinada praga produtos que possam ser prejudiciais à saúde da população, também o agricultor, no desejo de salvar a sua produção, não deve aplicar o primeiro inseticida que lhe aparece às mãos, pois estará colocando em risco a saúde de toda uma comunidade. É necessário que haja uma boa compreensão entre todos e que as recomendações feitas, tendo por base investigações oficiais e mesmo particulares, desde que bem-conduzidas e reconhecidas pelo governo, sejam respeitadas pelos vendedores, comerciantes e agricultores. De grande utilidade são as campanhas educacionais onde se orienta os lavradores e técnicos em geral, que antes da utilização de um inseticida, fungicida ou herbicida, o interessado examine bem as recomendações feitas no rótulo, seguindo estritamente as instruções ali contidas e controladas pelos órgãos oficiais. Se usados com critério e dentro de um alto padrão técnico, os inseticidas desempenharão satisfatoriamente o seu papel, sem colocar em risco à saúde de quem quer que seja.

\section{Bibliografia}

1. BROOKS, B. T. Chlorinated insecticides In: Bioligical chemistry. S. 1., CRC Press Inc., 1976. V. 2.

2. COURY, Tuffi \& RANGANI, G. Efeitos do arsênico sobre a cultura do algodoeiro em terra arenosa. ANAIS DA ESCOLA SUPERIOR DEAGRICULTURA LUIZDE QUEIROZ. 1945. V. 2 , p. $293-422$.

3. EDWARDS, C. A. Persistent pesticide in the environment. S. 1. CRC Press Inc. USA, 1976.

4. ETO, Morifusa. Organophosrus pesticide: organic biological chemistry. S. 1., CRC Press Inc., 1976. 
5. GUNTHER, F.A. \& BLINN, R.C. Analysis of insecticides and acaricides. New York, Interscience Publishers Inc., 1955. v. 2 .

6. GIANNOTTI, O et alii. Noções básicas sobre praguicidas, generalidades e recomendações de uso na graicultura do Estado de São Paulo. In: O biológico. 1972. p. 223 - 339.

7. METCALF. R. L. Organic insecticides. New York, Interscience Publishers Inc., 195/.

8. PIGATI, P. et alii. Resíduos de inseticidas nos solos do Estado de São Paulo. In: O biológico. 1983.
9. UNGARO, MAria Thereza S., et alii. Resíduos de inseticidas clorados e fosforados em frutas e hortaliças. In: O biológico. 1980. p. 129-34.

10. Resíduos de inseticidas clorados e fosforados em frutas e hortaliças. 19834. V. 2. (no prelo).

11. Resíduos de inseticidas clorados e fosforados em frutas e hortaliças, 1983. V. 3. (no prelo)

12. VANTIEL, N. Activities of the FAO/WHO; codex alimentarius comission in the field of pesticide residues. Autlook on Agriculture, 1979. 
